\title{
OPPORTUNITIES OF APPLICATION OF THE BALANCED SCORECARD IN MANAGEMENT AND CONTROL
}

\author{
Venelin Terziev ${ }^{1^{*}}$, Vanja Banabakova ${ }^{2}$, Oleg Latyshev ${ }^{3}$, Marin Georgiev ${ }^{4}$ \\ ${ }^{1}$ Corresponding Member of the Russian Academy of Natural History, Moscow, Russia, Professor, \\ Ph.D., D.Sc. (National Security), D.Sc. (Ec.), University of Rousse, Rousse, Bulgaria; National \\ Military University, Veliko Tarnovo, Bulgaria; University of Telecommunications and Post, Sofia, \\ Bulgaria, terziev@skmat.com \\ ${ }^{2}$ Professor, Ph.D., National Military University, Veliko Tarnovo, Bulgaria, v.banabakova@abv.bg> \\ ${ }^{3}$ Academician of the Russian Academy of Natural History, Moscow, Russia, Professor, Ph.D., \\ D.Sc., papa888@list.ru \\ ${ }^{4}$ National Military University, Veliko Tarnovo, Bulgaria, clementon@abv.bg \\ ${ }^{*}$ Corresponding author
}

\begin{abstract}
Modern organizations focus on the importance of strategic management and control over current and shortterm goals and their corrective role on the strategic success factors of the organization in the process of using the resources of the external environment, ignoring the challenges; as the priorities of the activity are to maximally satisfy public expectations, to minimize the spending of resources, to use its own priorities, to successfully overcome uncertainty and risk, to introduce the adequacy of management decisions against the background of reasonable and measured risk. In the study alternatives are discussed as the Balanced Scorecard model suggested by observations and practice, and implications are provided in regard to changing and improving the architecture of the Balanced Scorecard (BSC) as a tool for management and control in conditions of high variability and uncertainty of the economic and social environment. Examined are some models in place to develop and implement the BSC and on this basis are structured conclusions and recommendations in the following aspects: the organization's strategy, which involves the application of BSC and the inclusion of elements to develop key aspects of the strategy; the potential of the BSC model and its application according to the different needs of management; the needs of the process of developing and implementing BSC and to further expand the applications of the BSC as a strategic management tool requiring an assessment of the expected status and priorities in the control of the indicators included.
\end{abstract}

Keywords: balanced scorecard, management, control, development.

\section{INTRODUCTION}

One of the features of recent decades is the rapid development of concepts, models and technologies for corporate governance. Particular attention is paid to strategic management. The analysis of the activity of large and medium-size economic units operating without strategic management is a very risky venture. Research in this area has evoked the emergence of new paradigms, concepts and tools. Undoubtedly, 
assessment is a valuable management practice. One of the roles of measurement, especially in the form of balanced schemes, is to facilitate the verification of the course of action on events in the organization.

The starting point of the balance methods is the understanding that reliance on the financial indicators in the assessment of the achievement of the set goals in the organizations is incorrect. Adapting balance-toperformance analysis to new conditions, apart from paying attention to traditional measures, complements them with new indicators of expected status and development in the future. The basis for this type of analysis is the validation of the Balanced Scorecard (BSC) presented in the early $1990^{\mathrm{S}}$ (Kaplan, Norton, 1992, pp. 71-79).

The Balanced Scorecard (BSC) is a practical tool to help organizations implement their business strategy. Strategic objectives, criteria and action plans are formulated for each perspective. The continuous process of development of the balanced scorecard is focused on the reconciliation of those perspectives. The card directs the organization's efforts on the critical analysis of the future and its association with the content of the ideal.

The process of introducing BSC into the practice of each organization predisposes establishement and regulation by certain cycles and principles (Kaplan, Norton, 1993). Through the language of goals and incentives, a connection is created between all hierarchical levels of effective communication. BSC is distinguished by a logically bound and easy to understand architectonics for the essential expression of the adopted strategy. The emphasis in the overall analysis of the BSC model is on the logic of combining different criteria. It also has a retrospective character, because it illustrates the history of the organizational strategy.

The idea of looking at business from the viewpoint of a "card" is of considerable interest since the introduction of the model in 1992. The reason is that more and more managers find a need for more than mass-applied short-term reports, referring to the development of capabilities needed to the organization which will also be successful in the future, although these changes may deprive them of profits in the current year and lead to increased spending. This is the fundamental reason why companies need the balanced scorecard. This need is even more obvious for non-profit organizations, such as government agencies and non-governmental organizations, and it outlines other legitimate reasons why a balanced system is successful in the world of business and consulting services:

1. This is a timely idea. Outdated traditional measurement systems, as well as ever-increasing efforts to exist in ever-complicated conditions, provide great opportunities for the BSC.

2. BSC is extremely well-formulated and presented very extensively in a number of scientific journals and by leading consultants on scientific forums.

3. BSC looks simple but has a broad spectrum of nature. The advantage of this is that, at first glance, sufficient transparency and comprehensibility are found. Yet, in a more in-depth study of the concept itself, it becomes clear that the so-called "simplicity" is only apparent.

Prerequisites for validating the management model of a balanced scorecard can be addressed in several ways:

- The low efficiency and the one-sided direction of management control towards finance, and hence the deformation of the database when creating a strategy.

- The need to put into practice a wide-ranging model, measuring effectiveness, analyzing relations and registering trends and directions of strategic development.

- The reconciliation of financial and non-financial measures of activity - their role in the implementation of effective management and control at all levels.

Since 1992 until now, the interest in the balanced system of indicators has been steadily increasing. The concept provokes the improvement of many managers. In the BSC, performance criteria are combined with criteria that describe spent resources or activities, and this combination is an incentive, a peculiar driver of work. Well-constructed maps combine several perspectives and elements that are difficult to distinguish. They are tied to a system of goals and means. In this line of thought, it can be argued that the maps largely illustrate the business's ability to rely on assumptions about relationships between the individual coefficients and that these assumptions should be used to accomplish a particular task.

Contemporary requirements of business and social environment call for dynamic organizations with a high degree of autonomy for workers. Traditional financial control is not appropriate for this environment. Not only is the information it provides often obsolete and inaccurate to use as a basis for customer or product 
solutions. In addition, autonomous employees need goals and initiatives other than usual, based on profit and return on investment, and are modeled on revenue accounting financial reporting. Other landmarks are needed to indicate a way that is compatible with the full foresight or the concept of the business. The whole organization must embrace the unity of strategy and business rules that are based on a consensus among the necessary priorities. For these reasons, the BSC as a system has its place and role. The concept is an assistant in the process of reaching a common view of the business environment in the company. It enriches the management and control toolkit and strengthens them in a strategic direction, rethinking their effectiveness and provoking their improvement in functional terms.

The term „BSC“ includes not only the specific structure for the "card“ itself but also the process of its use. Thus, the concept of the BSC is a component of a well-developed management and control system focused on a strategic perspective and critical response to traditional management and control. Here one can see the connection between Kaplan and Norton's original assumptions of controlling the BSC with similar assumptions and the idea of the company's intellectual capital. In the presence of BSC, financial responsibility and management have been replaced by the richer picture of reality. Not that the monetary criteria have become less important, but also in this connection it is necessary to form a balance in the transition from financial to strategic management of the activity of the organizational activity (Терзиев, Стоянов, Марин Георгиев 2017, ст. 236-241; Terziev, Stoyanov, Georgiev, 2017a, pp. 26-31; Terziev, Stoyanov, Georgiev, 2017b, pp. 62-66; Terziev, Stoyanov, Georgiev, 2017c, pp.76-80; Терзиев, Стоянов, 2017a, ст. 76-81; Терзиев, Стоянов, 2017b, ст. 63-71).

\section{EVOLUTION OF THE CONCEPT OF THE BALANCED SCORECARD}

There is a growing criticism of traditional management and control as only justified on financial criteria. The reason for this is that conditions today differ from the conditions at the time when the understanding of the meaning of traditional management and control was established. The strategy that underpins the processes that meet the customer's needs is incompatible with short-term thinking, the result of focusing solely on the financial criteria.

Critical views on classical control are being formed as it generates certain management deficits because:

1. Provides misleading information in making decisions. The basis for decision-making in a company is generated by information on costs, revenue and profitability. Traditional financial criteria show the results of past activities. Such information may result in an action incompatible with the strategic objectives [3].

2. Does not take into account the requirements of today's organization and strategy. Focus on monetary criteria forces companies to ignore less tangible nonfinancial criteria such as product quality, customer satisfaction, delivery times, flexibility, time to develop a new product and a higher level of workers' knowhow. Criteria used record false signals about enterprise performance and profitability.

3. Encourages short-term thinking and sub-optimization. Financial control does not imply long-term thinking. It can lead to cutbacks in research and development, return to obsolete training methods, weak motivation and initiative programs, and delays in investment plans. So the main problem is "sub-optimization" over time, and the challenge is to strike a balance between short and long-term work.

4. Management based on financial criteria diminishes the role of control. The structure of management and control systems is determined by the need for financial accounting on external information. The company's shareholders are constantly asking for information about the business's performance so they can be compared with alternative investment opportunities. Only financial criteria do not provide reliable and accurate information about business development (Johnson, Kaplan, 1987).

5. Generates misleading information on cost allocation and investment control. The traditional basis for cost allocation - distribution of indirect costs based on direct costs - is obsolete. The relationship between direct and indirect costs has changed as a result of increased research and development costs, joint work rationalization of production, and so on. Mixed product subsidies make it difficult to assess the actual returns of each product. In addition, it is often not possible to assess the long-term development costs of a product. Costs should be allocated in a way different from the traditional method of standard additives.

6. Delivers abstract information to the employees. Another shortcoming of the financial criteria is that they do not mean anything to a large part of the organization, consisting of employees who do not find a link between their work and the figures in the different types of reports. The systems are too complicated and thus become an obstacle to the front line flexibility (Eccles, Pyburn, 1992, pp. 41-58).

7. The role of the business environment is ignored. Traditional systems built on financial criteria ignore the prospect of a client and a competitor and thus fail to warn us of the changes in the subject of the 
company's activities and in industry: the financial key ratios of most control-management systems are directed more inward than outward. The criteria are used for comparisons with past periods based on internally generated standards. It is so much harder to compare the company with its competitors, though that information is as important as the company's performance to achieve its goals.

8. Opportunities of misleading information. Today's leaders are inclined to use information from monthly and quarterly reports - a factor that tilts the balance in favor of short-term investment decisions. In addition, this short-term perspective allows the manipulation of financial criteria so that financial key ratios may be misleading and unreliable for analytical and decision-making purposes (Eccles, Pyburn, 1992, pp. 41-58). It is precisely the dynamics of the balance between attitude and state that sets the agenda for solving the dilemma: a document or a process is the BSC model. When talking about the BSC it is considered that success should reflect the balance between several important elements of work, the reasonable balance between attitude and the state of developed and developing components [6] (Friedag, Schmidt, 1999). It is equally important that the BSC is shaped as a document of achieved and expected results. It is then an alternative way of visualizing the business plan.

In the early models, the BSC is considered as a value measurement method. In these cases, it is very difficult to look for serious reasons for the process to be linked to strategy management and control. At this early stage, the development of BSC is tied to concrete initiatives and events, planned and budgetary provision. There is mutual influence between the shape of the BSC and the entire planning process, in particular the budgeting process. It implies a balance between short and long-term planning and an opportunity to set the necessary strategic direction for the efforts of each member of the organization. The BSC often creates occasions for discussions that might not have taken place without it, but are important because of its use. Thus, a document is formally a BSC, but it also contains much more.

The idea goes far beyond just creating an evaluation system. Although there are many views on the BSC, too many other content is also included in this concept. Practice has shown that BSCs have different applications - from budget management to strategy management. They all have a common trait: their emergence in recent years is driven by the need to measure and manage both the efficiency of the activities of the organizations under consideration and far more complex processes such as the implementation of strategies. Underlying the concept of BSC is the idea of forming an innovation system to measure the activities of organizations.

At present, organizations and corporations operate in a new kind of economic environment based on knowledge where it is necessary to manage practically non-measurable activities such as innovation and human capital. Organizations themselves are aware of how new phenomena exist in the new kind of economy, such as people's knowledge, new technologies and software products, corporate culture that fosters innovation. It is reported that organizations do not have the right tools to successfully implement their new strategies and to successfully control them (Stoyanov, Tranev, 2016, pp. 298-304).

Based on the examined models of the BSC, the following conclusions could be drawn (Terziev, Stoyanov, 2015):

1. In the evolution of the BSC, several major development lines can be highlighted:

a. development of the BSC as a measurement tool and a tool for better reflection of the status and development of organizations;

b. development of the BSC as a measurement instrument in strategic management and as a control instrument;

c. development of the BSC as a measurement and management tool for the needs of the different levels of the organization.

2. The development of the BSC as a measurement tool marks different stages of its improvement, which are related primarily to the enrichment of the parameters included in it and to the study of the relations and the relationships between them. Based on the gradual understanding of the new success factors of organizations, the range of indicators included in the BSC is expanded and clarified and approaches and methods for measuring their meanings are developed and implemented. The centerpiece of this process is the increasing attention and ability of organizations to explore the relationships and relations between different indicators and to rank them according to their role in the strategy. As a result, at the beginning of the century, significant leadership in implementing the BSC achieved the necessary maturity of opportunities for operationalization of the strategy in indicator models.

3. As early as the first years of its promotion, the BSC began to be validated not only as a tool for 
measuring and modeling organizations but above all as a tool for modeling and implementing the strategy. Initially, the views in this regard are too general and represent the BSC as a strategic management tool. Gradually, emphasis has been placed on the role in controlling the implementation of the strategy, and in the last years, they have increasingly specified their role as a strategic control tool. The understanding that the card's purpose is to highlight the key controllable parameters in the strategy that has already been developed and to ensure that their meanings and implementation measures are targeted is becoming more conceived.

4. Achievements in the development and implementation of the BSC at the organization and enforcement level and as a tool for strategic control lead to the dissemination of this process in the structural units of the organization. The leading implementation organizations achieve the formation of a hierarchically built system of BSCs, including the individual level. This is how the BSC is fully validated as a tool for control and evaluation and a central factor in targeting efforts at all organizational levels to implement the strategy.

5. The evolution of the BSC in all directions has been stimulated and accelerated by the development and dissemination of computer-assisted management technologies that facilitate the use of the BSC. Information technology related to BSC implementation is not yet integrated organically into ERP systems, but in many cases they are successfully upgraded or run in parallel as a module of management information systems.

The BSC was originally designed to give managers structured information from performance criteria based on a combination of leading and delayed indicators. But from the moment of its introduction, BSC has gradually evolved from a tool for organizing criteria into a strategic control mechanism. It evolves both in its construction, in the process of creation and in use patterns. This evolution goes through three stages, reaching what is now called the third-generation BSC [8]. Third-generation BSC is a methodology for managing and evaluating the work of organizations on their way to achieving strategic goals. But years of practical experience and scientific work are needed to overcome the shortcomings of the original model, which is most often associated with the failure of the BSC to be an effective tool for corporate governance and control. Typical problems such as lack of ownership of management, monitoring only financial criteria, and the inability to force the management system to develop and improve are already addressed.

The ideas of the third-generation BSCs are based on the following key concepts of business management and strategic development control. The model weight is placed on the following items from the content of organizational management:

- Cause: Finding and developing the activities needed to reach key results and implement strategies.

- Training: Use feedback to find ways to improve and improve your work.

- Ownership: Use consensus to make everyone aware of what needs to be done and to engage fully in the process.

- Communication: providing clear and unambiguous information for goal disclosure and optimization of organizational activity.

A significant breakthrough during the evolution of BSC is the realization that the successful use of this tool is not only dependent on the use of proper methods for selecting the criteria included in it, but also by the fact that organizations are implementing the right management processes that enable it to be effectively used by managers. These statements provoke the development of the BSC as a management and control framework, which proves the hypotheses by taking them out of the following factors:

- A pronounced wording for a "desirable state" or a strategic destination (positioning);

- Medium-term strategic objectives to be assessed, decomposed into activities and outcomes and, if necessary, standard prospects;

- Specific and clearly defined goals, interpreted on the basis of vision, mission and strategy;

- Priority initiatives relating to the structuring and implementation of strategic objectives;

- Analysis of expectations and organizational needs and on this basis formation of criteria for defining key characteristics, defined as a system of criteria.

The last-generation effective BSCs are those developed with the active involvement of the management team that will use them to manage the organization. Essential to success is the application of a technologically sound and appropriate creation process. The use of an "easy" process is recommended, according to which the management team itself defines the "content", which largely implies a positive and 
timely outcome (Stoyanov, 2016b, pp. 23-26).

The analysis of the evolution of the concept of BSC and the evolution of the concept of strategic management and control clearly reveals similarities in terms of development trends and alternatives for improvement, which lead to the following implications:

First. The BSC model from a value-enhancing organizational performance tool is transformed into a tool for managing and controlling the strategy. In this way, it can be assumed that a kind of expression of the transition in managerial thinking is formed in terms of management control systems in which the financial burden is redirected towards strategic control. Improving the concept of strategic management and control and modeling of its model area has a significant impact in forming a model prototype related to the concept of BSC.

All three models of strategic control have a very strong influence on the first generation BSC. From the threestep model, the principle of linking the environment with the strategy-building process is borrowed. From the process model comes the trend that deepens the development processes of the organization, namely the organizational training as a form of development of the training organization. From the conceptual model, that the control can be realized through criteria and objectives, which are differentiated in the BSC as indicators, summarized in several main areas /perspectives. By examining these concepts and their development, it can be concluded that in the process of mutual influence they aim to improve.

The transition to the second generation of BSC resonates fundamentally and predominantly in the development of the model area of strategic control. The deepening of the strategic orientation on the BSC reveals the emergence of overlapping and generalizing indicators, which in the strategic management and control systems are defined as criteria for the rapid preliminary, respectively the subsequent, reverse control. Here, however, BSCs record a certain priority in the establishment of the strategic relations model.

Second. Developing the idea of the learning organization finds a particularly strong charge in reconciling strategic control concepts and BSC. Though strategic correction models have been marked and corrected by the feedback on the behavior of the organization under review, this process has recorded a deepening in BSCs. As the most organized form of feedback, corrective actions, if necessary, can take the form of seminars to discuss the recorded results and expected changes in organizational behavior. In this case, we can talk about a particular form of organizational self-improvement and training. This deepening trend brings about the creation of sustainable value by the organization, provoking the improvement of the methods of use and mobilization of its intangible assets - human capital, databases and information systems, sensitive high-quality processes, customer and trade relations, for the innovation and highly developed organizational culture. Perhaps this is the most significant evidence of the recent trend of shifting the focus from an economy based on tangible assets to an economy based on intangible assets, knowledge and service.

Third. As the most important moment in the process of analysis on the relationship between the concepts of strategic management and control and of BSC is their reconciliation and the formation of a qualitatively new model. Theories prevailing among the leaders of governance have not created a particularly serious and universal strategic framework. Strategic doctrines are centered on shareholder, customer management, process management, quality, key competencies, innovation, human resources, information technology, organizational structures and training. And while each of the above-mentioned strands is in itself extremely important, none of them provides a thorough and integrated approach to strategy development. Even the theory of M. Porter (Porter, 1996, pp. 44-78), based on positioning for a competitive advantage, does not provide a comprehensive vision of strategy. It is here that we can speak of a unified, consistent system of realization of management and control over the strategy that results from conceptual eclecticism and model consolidation. This new model, a new strategic framework, exposes in a new way the importance of strategic management and control, based on a system of indicators and a portfolio of perspectives linking efficiency and strategies, between short and long-term results, forming a unity between the present and the future.

These three implications suggest that in the management and consulting practice, the BSC is validated and improving as a tool for strategic management and control. At the last stage of the evolution of the concept, the indicators for measuring the performance of not only the organizational activity, but above all its strategy, are being revolutionized. Along with the imposition of strategic maps as a tool for effective management and precision control, the latest card designs are presented as a brilliant, accurate and holistic method to consolidate the most critical moments in the art of modern governance and the challenges of modern control.

\section{THE BALANCED SCORECARD- A PARTICULAR FORM OF MANAGEMENT THINKING AND CONTROL}

The Balanced Scorecard is a particular form of management thinking and control, implemented through a 
series of actions. This individuality and uniqueness is predetermined by two components - on the one hand the uniqueness of each organization and its strategy, and on the other specific, specific solutions for management and controlling through certain initiatives and events.

Each organization sets out perspectives, timelines and indicators according to these characteristics when introducing the BSC as a management and a control tool:

1. Perspectives - due to the opportunity of covering different perspectives, analyzing and fixing their weight against strategic goals, emphasizing in this process the strategic success factors.

2. Timeframe - due to the opportunity of organizing the strategic actions in a concrete sequence, by putting strategic factors in time in the realization of the process.

3. Indicators - due to the opportunity of indicating and encompassing the logical and temporary interrelationships between the strategic factors, which are at the same time reconstructed as a complex of attention zones.

In its original form, the BSC model covers four main areas. The first includes finance - it consists of parameters such as: growth, yield, turnover, shareholder value, etc. The second concerns the users - in this segment are introduced measures that provide information about customer satisfaction. The third area concerns internal processes - identifying those processes that maximize added value. And the fourth area is tied to the continuous addition of knowledge and development to the organization.

Today's managers recognize the impact of the criteria on work and strategies. Resulting evaluation should be an integral part of the management process. The Balanced Scorecard gives the administrative staff a detailed structure that transforms the company's strategic goals into a clear set of benchmarks. It is more than an assessment exercise, it is a management system that can motivate serious improvements in such critical areas as product, process, customer and market development (Stoyanov, 2016c, pp.153-164).

The BSC gives the managers different perspectives from which to choose criteria. It complements the usual financial metrics with work, customer, internal processes, and refining and optimization activities. These criteria differ from traditional ones. It is clear that many companies already have a sufficiently large set of physical and operational criteria for their activities. But these criteria are directed downwards from the strategy to the particular operation and are tailored to the specifics of these processes. On the other hand, the criteria of the BSC are set in the strategic goals and competitive needs of the organization. By driving managers to select a limited number of critical metrics from any perspective, the BSC accelerates the ability to specify strategy, mission and vision (Terziev, Stoyanov, 2015).

Moreover, while traditional financial criteria show what happened over the past period, without showing how managers can improve their performance over the next, the BSC is also a cornerstone of the company's current and future success. Furthermore, unlike conventional measures, information from perspectives provides a balance between external criteria such as operating income and internal criteria such as developing a new product. This balanced set of criteria reveals that the replacements that managers have already made between the activity criteria encourage them to achieve their goals in the future without replacing key success factors.

The BSC is the language, the control point of the background, on which all new projects and types of business are evaluated. It is not a template that can be applied to a variety of business or industry. Different market situations, product strategies and competitive environment require the use of appropriate specimens (Ehrmann, 2000, pp. 33-38). The success story of is in its transparency, allowing the observer to understand the chosen competitive strategy through a criterion system.

The above discussion is a good reason to make the following considerations:

1. The model of the BSC, compared to the management models that were prevalent in the early 1990 s, changes the logic in structuring organizational performance indicators. In this respect, it is heavily influenced by stakeholder theory, which postulates the organization's drive to meet the requirements of key agents in its environment. As a result, the BSC model defines several key measurement and management perspectives in which these requirements - finance, users, internal business processes, training and staff development are expressed. In this respect, the model creates better than the existing conditions for achieving the unity of the organizations' potential with the characteristics of the environment in a strategic aspect.

2. The BSC model also takes into account the dominant role of value-for-money theory in business organizations and the prospect of finance. Fundamental importance for structuring the model for each organization is the study of causal relationships and dependencies between indicators from other perspectives and those from the perspective of finances. Unlike previous management models, however, the 
model of the BSC includes in these relationships a considerably wider range, mostly intangible indicators. Thus, the model upbuilds primarily on financial models and reveals the success factors.

3. The model of the BSC fundamentally resolves the issue of creating prerequisites for the implementation of the strategy. Its design implies operationalizing the strategy in a limited range of key causality-related dependencies, which facilitates the presentation of strategic thinking among broad circles of performers. This makes the strategy transparent and simplifies management processes.

4. The coverage of a wide range of non-material factors of organizational success requires the introduction of new types of systems to measure intangible parameters essential to the functioning of organizations in management practices. Towards the end of the last century, this stimulated the active development and implementation of modern methods to measure the satisfaction and loyalty of clients and staff, the development and evaluation of intellectual capital,

5. The BSC model is very much built naturally and organically over existing management systems, including those for budget management. The requirement to define initiatives to achieve strategic goals on the implications of the indicators included in the model creates favorable prerequisites for strategic budgets, considered as an indicative framework for operational and tactical budgeting.

\section{THE BSC AS A TOOL FOR STRATEGIC MANAGEMENT AND CONTROL}

The very first reflections on the concept of the BSC prove that the organization can be seen from concrete perspectives, as the BSC model achieves the most tight link between the short-term operational control and the long-term strategy (Stoyanov, Tranev. 2016, pp. 197-203). In this way, the company focuses on a set of critical key ratios that reflect the state and trends in certain planned areas. In other words, the company is forced to control and analyze day-to-day operations as they affect the long-term development, including its strategic prospects. Consequently, the concept of the BSC contains three time dimensions, analyzing registered results, regulating current activity and focusing in the future.

The BSC is a method of reaching agreement and realizing control over where an organization follows its strategy. In business and the public sector, key indicators can be found in abundance. The difference is in focusing on a deliberately chosen set of criteria - little enough to be observed - and on their use to achieve and share a common view of the organization's strategy for its future development. The agreed set of criteria, formed on the basis of a necessary, reasonable balance, reflects the strategic choice of the organization.

The selected criteria can be seen as a complement to financial control and as a means to reduce the risk of a harmful short-term approach, while giving a clear idea to the employees of the organization about their work, and expectations about the company's future. Some scientists talk about changing the approach from financial to strategic control (Terziev, Stoyanov, 2015a, pp. 303-322), i.e. from a specific direction in the management, to change the focus of attention to the overall organizational strategy. The question really concerns the essence of the economy more than the monetary method. A good economy means good resource management.

Modern organizations are much more than a skillful investment of capital. It is important for each leading manager how to manage talent, market position and accumulated knowledge. The perfection of a simple concept predetermines the universal nature of the BSC model and its wide perimeter of application, promptly demonstrating the tangible and intangible benefits of reconciling financial and non-financial criteria.

In most organizations, processes of strategic planning and operational funding exist independently of each other and involve separate organizational structures. The process of strategic planning is permanent, defining long-term plans, goals and strategic initiatives, usually taking place by deepening substantial trends registered on an annual basis. On the same basis, it is endorsed by senior management and the organization's budget. It consists almost entirely of numerical financial indicators, which usually mark the link between the strategic plan and the organizational goals. If an organization wants to establish a link between its actions and strategy, strategic and planning should be linked to operational funding. Strategic targeting processes express the business unit's drive to achieve excellent results on strategic indicators of the prospects shaping its BSC. Resources are being used and initiatives are being implemented to ignore the differences between the current state and indirect goals for a prolonged future period (Muller, 2000).

One of the most significant alternatives for genuinely controlling the validity of strategies and the effectiveness of strategic planning is the formulation of specific short-term goals on the parameters that form the BSC. The intermediate controls in question are a real expression of the senior executive's performance on the pace and outcomes of ongoing programs and strategic indicators initiatives. Such detailed short-term 
financial planning is important, but the budgeting process should also include expected performance from other areas involved in structuring the BSC. This means that the executive management should provide, as part of integrated planning and budgeting, short-term monthly or quarterly performance and performance indicators for its users, innovative and operational processes, and the process of synchronization between employees, systems and organization. These key milestones in the planning for the next year express the expectations for short-term achievements over the long-term road to realizing the strategy chosen by the organization. If the long-term plan definition process is properly implemented, the short-term budgeting process will consist of bringing the first year of the multiannual plan into current budgets for the objectives and indicators across all BSC lines.

Considering the necessary strategic / budget reference, a new direction is emerging to improve the BSC model. In this process, two management problems are simultaneously implemented:

1. Increase operational-tactical efficiency and related budgets.

2. Realizing successful strategic development through reasonable strategic planning. The combination of the two decisions defines the new content and functionality of the BSC as a tool for managing and controlling the strategy.

In this line of thought, the relationship between strategy and budget, strategic planning and budgeting is a procedure underlying the effective analysis and detailing to implement the smooth transition from a high-level strategy to the creation of a budget for the implementation of the current activity. The strategy sets the organizational development line for the 3-5 year period in its implementation, while the annual budget provides the first year of this process and marks the links between current and strategic goals.

The current and effective management and control model of BSC has identified certain gaps and problems, the solution of which is the path to its improvement and enrichment in a meaningful and functional aspect. Is it possible to formulate model strategic goals of the organization, control strategic and development, engage all personnel and all that leads to success and stable development? BSC is the modern management and control model through which this task can be realized. Along with the Balanced Scorecard, it is possible to conduct flexible and effective management and strategic controls using not many but relevant indicators.

As a starting point for effective governance and control, there is a balanced reconciliation of various indicators necessary to reflect the organization's activity and the construction of a logical system such as BSC based on proven causality. The realization of this process and its specificity are accompanied by specific issues, whose analysis and solutions are an alternative for improving the BSC as a model for real control. Everyone who knows the life of the organization knows that there are a number of control systems that affect its day-to-day operations. However, there is no systematic understanding of why and how these systems are used as a means of achieving certain programs (Simons, 1995).

By organizing their management system based on the structure of the BSC, managers can achieve their most important objective - bringing the strategy into operation and controlling it. When organizations make the crucial transition to turning their strategic vision into action, they realize the true upsurge and take real advantage of developing and implementing strategically BSCs. The results of the initially developed BSC always lead to a series of management processes that mobilize and reorient organizational efforts. The development of the original BSC in an organization is achieved on the basis of systematic consensusbuilding processes and clarifying how the mission and strategy can be brought into a system of working objectives and indicators.

As a result of an in-depth study of good practice among organizations that have embedded and using BSCs, there could be drawn a model of five principles that organizations could follow in transforming their strategy into concrete actions and implementing real, strategic control (Terziev, Dimitrova, Stoyanov, 2015, pp. 9-25).

The first principle claims that change should begin at the highest level. The idea is that senior management initiates the implementation of the strategy, firstly fixing the organization's vision and goals, demonstrating personal interest and engaging staff awareness with the upcoming change.

The second principle considers that the strategy needs to be translated, that is, detailed, bound by deadlines and operational plans. BSCs are being modeled at this stage to analyze the links between the different elements of the strategy, to formulate objectives and their measures, and to identify strategic initiatives.

The third principle is justified by the need for the organization to be able to implement and implement the corporate strategy. At this point, it is imperative to develop BSCs with indicators for lower business units /departments, workshops, to identify opportunities for synergy in order to achieve maximum added value.

The fourth principle identifies the need for the strategy to become an essential part of the work of each 
employee in the organization. This is a difficult process due to the fact that it is related to the development of individual BSCs that contain individual goals and consider the relationship between each employee's personal contribution to implementing the company's strategy. Here, it should be noted that the practical application of BSCs as a form of individual development and control makes sense and a logical explanation especially for key individual positions /consultants, representatives, etc./ where their activities have a significant impact on organizational efficiency, which causes the application of BSC to be financially secured and objectively necessary. An essential point here is to find the intersection between individual and corporate values. Success at this stage is crucial because, although the strategy is formulated by the management, its implementation depends on the staff working in the organization. By aligning and consolidating goals and incentives at an individual level with those of the organization, effective communications transparency and maximum management and control performance are achieved.

The fifth principle has a generalizing character, imperiously pointing out that the strategy must become a continuous and permanently improving process. It is at this point that different practices are being developed in relation to resource management, the process of training organization, and the updating of initiatives and control measures (Botta, 2001, pp. 16-20).

\section{PROBLEMS IN THE APPLICATION OF BSC AS A MODERN TOOL OF MANAGEMENT AND CONTROL}

The problems that can be committed to the implementation of measurement and control of the activity through the BSC and its application as a modern management and control tool are determined by the specifics of the particular organization under consideration, the sphere/branch in which the potential of human resources is realized. Building on the accumulated experience and shared experience in designing and implementing BSC, several issues arise:

1. At the level of indicators - more common problems can be identified, such as:

a. deformation of output data;

b. short-term character of the indicator/short life cycle/;

c. indicators without registered trends, in the context of the formulation of forecast and planned values;

d. indicators that do not take into account efficiency;

e. indicators with a fictitious character;

f. "behavioral" indicators - take into account the behavior and mood of the team rather than the actual increase in the magnitude;

g. "competitive" indicators - stimulate competition in the organization, without taking into account the efficiency of the activity and to manage and control.

The introduction of each indicator in the BSC process is related to a specific expedience and a system of actions controlled by a delegated, responsible team. In addition, the content of the specific indicator is also linked to the incentive and remuneration system, which forms a high responsibility and serious motivation. It is on the basis of this logic that control measures are formed.

In the course of continuous monitoring in the work with the BSC, the accent is on the recording of deviations from the adopted standards and imposed norms. Early diagnosis of these deviations signaled the emergence of new trends generating new ideas for improvement of the values for the given indicator, and hence from the perspective of the BSC.

Depending on the severity of the different sensitivity, a part of the indicators can be classified as outperforming and the rest as lagging indicators (with a generic, resultant character). In particular, the balance between the different types of information provides the development of the BSC as a process.

2. At the perspective level, the issues are related to:

a. the functionality of the links between the composing indicators;

b. reconciliation of different viability indicators;

c. the quality of the relationship with the other perspectives.

Regarding the perspectives and their intermediate role as a constructive element of the BSC control system, the functionality of the relations between the composite indicators and the relations with the other 
perspectives is important. The functionality of the links between the indicators in the perspective itself determines the perspective of the process of modeling the card itself. Due to the fact that the validity of the information provided in different indicators is different, sometimes their relationship with other indicators becomes incompatible and the registered trends are invalid. The interrelationship between prospects, resting on significant correlations between their indicators, forms the balanced character of the BSC and reveals the opportunitie for efficiency control.

\section{At the organization level:}

a. uncertainty of the economic environment and frequently changing legal framework for mission, strategy and vision formulation;

b. a logical way of reconciling information of a different nature and content;

c. shortage of qualified staff in forming teams advising the creation and implementation of the BSC project;

d. lack of highly customizable software products and platforms to facilitate work on BSCs, both composing and putting into action.

The above-discussed problems provoke the development and improvement of BSC as a management and control tool in several directions:

First. In terms of content, the individuality and uniqueness of each organization under consideration predetermines the construction of a particular BSC with a strictly individual set of perspectives and indicators. As a critical remark on the BSC, a number of consultants mention that it has two disadvantages, although both can be overcome relatively easily. The first is related to the perspective of customers, which implies ignoring the broader market outlook. It's important not how the business looks in the eyes of customers, but how it looks against the background of competition. The second and most significant flaw is that no suppliers are taken into account. It is believed that if business improves itself, everything will be fine, but nowadays, when there is a growing resource depletion, the interdependence between activities is continually deepening, especially in the area of production. It is this fact that increases the need to introduce new sets of indicators that create new perspectives. The high dynamics and the huge amount of information on the creation and functioning of each outlook predetermines the use of indicators with a partial resultant character. The recording of specific development trends in causal relationships between indicators in a single perspective can form a database for differentiation and indicators of a complex nature.

Second. There is also a special topicality among the analyzed problems and the involvement of the BSC control projects with the creation of software products. The first software systems start with a high value of these elements of the content information that can link the data to the criteria. Using modern systems they can facilitate timely diagnosis and intervention in response to observed processes, increasing the ability to store and work with these features as a database. This is the main feature of leading balanced scorecard software systems. Here the refinement can be done to maximize adaptation of the specific product and its version to the individual specifics of each organization. As a disadvantage of the software product range, it is possible to register the ignorance of the subjective factor in the implementation of control and corrections on the activity, due to the fact that besides the given parameters in each individual solution there is a combination of managerial flair and subjectivism.

Over the years, since the balanced card exists, ин its physical structure, its use, and the process of its creation as a tool for management and control in organizations, many changes have been made. This evolution, at least as far as the parameters mentioned above, is largely due to empirical evidence, drawn mainly from observations of weaknesses in the process of creation, rather than the structure of the original idea. The need for a process of creation that makes a more appropriate selection of criteria and part of the collective view of the management team is causing major changes that are being made in the second and third generation of BSC. But while empirical developments remain at the edges of the evolution of the BSC, some aspects of the evolutionary rationale correspond to existing academic perceptions related to organizational management and strategic thinking and control (Terziev, Dimitrova, Stoyanov, 2015, pp. 925).

Combining developments on the principles of the BSC and the theoretical aspects of control and management processes is a positive indicator that the more recent ideas of the process of creating a balanced map and its structure are really "better" than the original concept of Kaplan and Norton insofar as they are more likely to have a beneficial impact on the organizations that use them. Although modern BSCs are much better than the original ones, there is still room for improvement in potential areas for further clarification of topics for future development and research: 
1. Clarifying the links between the different types of behavior of the managers and the information, which facilitates and quite often focuses their intervention. In this area, there is a central distinction between operational and strategic control and this is well-formulated and regulated in the documentation. However, there is a need in the literature to describe more mechanisms to influence more effectively the behavior of the person in charge of organizations and their key processes.

2. Exploring how to reconcile the report with the job management. It is often the case that the data in the organization's management system does not fully cover the business (for example health and safety measurements, operations metrics, finance, human resources, markets, etc.).

3. Discussing the relationship between the application of BSC in large organizations and issues related to internal communication in units. When the balanced card is developed from top to bottom in the organization, it can be used successfully as a means of communicating the strategy, but its exact benefit should still be explored. When this process is realized from the bottom up, a higher detail is recorded, blurring the strategic purpose of the model.

4. Exploring the most appropriate ways of novelty in the concepts of criteria (eg. intellectual capital and others) to be successfully used in the process of creating the BSC applied in the company concerned, without reducing the importance of contributing to this process by managers who are not familiar with new concepts. However, if the management team does not consider it necessary, it will not include them in the structure of the BSC. If it happens that a consultant "embedds" innovations that are potentially useful, they will not be used by the management team if it does not understand them. This scenario demonstrates that the interaction of the balanced map with the other management team concepts and its improvement depend on the skills and education of the team members and the high degree of synergy and consistency in their actions.

5. Developing a perception of the value of the balanced card and, if possible, applying monetary values in the organization scenarios before and after it. A key criterion for putting the balanced card into use in organizations is the ability to show an effect.

The evolution in the model field of certain rational models and their reconciliation with alternatives and concrete solutions to problems provide real grounds for considering that the perimeter and the high efficiency of the management and, above all, the control (including the exercises on the strategies) rates of transformation and improvement and their potential is becoming more and more important.

The idea and conceptual features of the BSC imply the creation of certain conditions and the definition of organizational and institutional prerequisites in order to proceed with the design of such a management model. The goal set for materialization through the BSC methodology predetermines some form, structure, and content. It is for this reason that every detail (element) of the structure proves that its content determines the selected formal expression. Referring to the principles of constructiveness, continuity and systemic logic, indicator-criteria-perspective-card makes the BSC model into a constantly evolving process and transforms the organization itself or a system in which it flows as a self-improving structure, regardless of scale.

The review of design and commissioning technology form and imply the understanding that more commonly used BSCs are inherently a macroeconomic model for organizational development. The rationale for this can be found in the key presence and role of the principle of imparting quantitative characteristics and setting time boundaries to the tasks that are mainly directed at the implementation of strategic models of thinking and behavior. Resting on this logical line, the technology of creating and introducing by its nature and content is a process of continuous adaptation of the organization or the system to the changing conditions of the social environment and the stated expectations of society.

Finding a conceptual similarity and proximity between the strategic management and control and the BSC is grounded in two key trends that change the understanding of modern and effective governance. One focusing on strategic development perspectives, and the other - developing and improving intangible factors for organizational success.

Forming an assessment and creating conditions for ongoing and systematic monitoring would provide the entire institutional system with clarity and transparency not only for the growing role of strategies and intangible assets in the present day but would give a realistic picture of the financial implications of all activities, and the control would thus be far more effective. 


\section{APPLICATIONS OF THE BALANCED SCORECARD CONCEPT IN RELATION TO SOCIAL DEVELOPMENT}

The successful social development is a result of an effective governance and control. This requires all operating organizations to continuously improve their measurement systems. The main message to those responsible for the development, improvement and implementation of these systems from the outset of the process is the identification of the role of the performance measurement system for the activity itself. The creators of these performance measurement systems and measurement methods are actually looking for sophisticated ways to reconcile work-based behavior in the particular organization with its overall strategic goals. In this context, the measurement allows managers to determine whether the planned events are being implemented in practice, whether the activity is improving and, if so, whether the organizational activity is secure for a long period of time.

Nowadays, managers from all sectors of the social system on a global scale face the dual challenge of how to mobilize their human capital and information resources and how to transform their organizations towards new strategies in line with the high requirements of their informed and demanding users and customers. Institutions and organizations generally respond to this challenge by formulating new strategies and redirecting, through declaring new inspirational missions and concepts, to delivering increased value to their clients and partners. But the major problem they all face is their inability to successfully implement their new strategies due to management difficulties and the resulting control over the measurement process and strategic development based primarily on intangible assets .

The data obtained from the system for measuring the indicators enables the organization's strategy and the principles of its practical activity to be adjusted, as well as the feasibility of the measurement model. However, looking at just one indicator can not give an accurate idea of the status of any system, whether it be a business or a non-profit structure. The need for a balanced set of measures is becoming increasingly important, both in terms of efficiency and strategy. The advantage of this approach is that when using a combination of several key metrics, results are less likely to be affected by manipulation of the information reports. Each factor attempts to give a relevant indicator of the performance of the company or its condition and can be used independently as an indicator of financial viability or as part of a certain perspective.

The BSC is a rational summary of accumulations in the field of measuring performance indicators, which is done in an appropriate form and demonstrates in practice how it can achieve a real value as a result of management on the basis of intangible assets by combining them with the organizational strategy. The introduction of a new content of the measurement methodology with the use of its three roles - for compliance with standards, for verification and refinement - differs significantly and it is much wider than the traditional concept of measurement as a tool for strategic management and relevant control. It is not based on the understanding that behavior can be controlled by measurement. It is based on the view that BSC is an instrument that is used to improve the course of institutional development and that it is precisely this move that has other features to be measured and managed in a new and different way (Terziev, Stoyanov, $2015 \mathrm{~b}, \mathrm{pp} .214-229)$. On this basis, the sophisticated measurement methodology goes beyond the standard of confirmation of compliance and is established as a methodology for measuring strategic stability, which more fully responds to public interests.

It is also interesting to devote little attention to the application of the concept of BSC and its application on a larger scale. Specifically, there are significant and large-scale plans involved with the future of society or the state, and with cases involving social programs, the realization of which is linked to a system of design decisions.

One of the central problem areas provoking an expansion in the quest for management theory and practice at the beginning of the 21 st century is related to the implementation of effective strategies, not only aimed at specific organizational structures, byt also implying a balanced socio-economic development. Despite the versatility of efforts and the record of significant results, the theoretical summaries have not reached the necessary integrity and a high degree of completeness. The main achievements are mainly in the heuristic plane of scientific knowledge and it can reasonably be said that they do not have a sufficiently systematic and complete character (Stoyanov, 2016d, pp. 159-162). A publicly significant and persuasive example of multiple recurrences of this deficit is the general development of the society itself, viewed as a state and its systems, and more specifically in the behavior of actively participating in its functioning. Authorities in scientific thought argue that at this stage the key issues that provoke serious demand but also immediate solutions are several: poor and low-performing markets, inadequate corrections by the political system and deepening of the principle of injustice; the lack of synergies in the work and the interaction between the political and the economic system (Stoyanov, 2016d, pp. 159-162). 
The presence of these tendencies proves that the problems of the society predominantly stem from the markets, which are interpreted as the main social motive for development and improvement. The claim of their inherent resilience is disproved by the global financial crisis, which transforms them into extremely unstable and generating devastating consequences. Critical analysis of the emerging situation shows a threateningly decreasing market efficiency based on poor satisfaction of ever more specifically stated, socially significant needs, ignoring investment interests and total depreciation or deletion of huge resources present in the form of human capital, technics and technology.

This situation is largely due to the fact that the efforts of the scientific community in the last thirteen years of the last century were focused mainly on the development and modeling of strategies and not on the process of their realization and improvement. As a result, significant scientific and applied results have been recorded as a great model, such as a plan, a doctrine and a strategic position (Mintzberg, Ahlstrand, Lampel, 1997, pp. 11-22). In the early $1990^{\mathrm{s}}$, however, the issue of strategy implementation came to the fore. It was aware that even good strategies require special scientifically grounded mechanisms for their realization. At the same time, it became increasingly obvious that the rapid, unexpected and radical changes in the dynamic environment did not allow the moment of action to wait until the development of a comprehensive strategy and the processes of development and implementation had to be considered as running in parallel. This is reflected in the emergence and establishment of the concept for the evolving strategy.

The practical development of this problematic area of social management has put economic science, in particular, in the face of social sciences, the need to develop the theoretical and practical aspects of effective publicly relevant governance and relevant control within a short period of time. It has been concluded that the existing principles in this respect do not sufficiently serve the needs of the objective reality and the practices in it (Stoyanov, 2016e, pp. 52-57). As a result of their closer ties to practice, leading analysts and consultants were more aware of the problem and were moving their efforts in this direction. Due to their specificity, the searches conducted are mainly instrumental, resulting in a number of new tools such as a balanced scorecard model aimed at optimizing operations and structuring strategies and exercising a real control over them. However, it should be noted here that when the focus of attention is placed on the state as an organization for most of the strategies and doctrines it is difficult to claim that they are associated with an organized and systematic control.

On the basis of the presented trends evolving in the objective reality and the improvement of the sciences for the society, and in particular in the social management on the theoretical and conceptual basis, changes are also registered in the model of the behavior of the state, interpreted and perceived as a supreme, socially structured institution. In fact, the leading management concepts of recent years have provoked changes in ongoing and state-coordinated social development processes and rethinking the process of shaping targeted social strategies (programs) considered as a regulated and controlled program (Stoyanov, 2016f, pp. 63-73; Terziev, Dimitrova, Stoyanov, 2015, pp. 27-46).

Cardinal changes are reflected in the following aspects:

1. Social development, driven by in-depth social programming, becomes a process consolidating the potential of targeted social doctrines and public interests.

2. The state has transformed its behavioral model and has been reforming its structure accordingly, thereby making it a strategically focused, self-perpetuating, functionally-based organization;

3. Social programs from a tool for legitimate measurement of socio-political applications are transformed into a modern canonized method of legalizing modern, socially significant strategies, as well as an established opportunity to interpret and prove chains of hypotheses and assumptions constructing successful strategic doctrines and simultaneously as a specific tool for an effective management control at the highest level in the social hierarchy.

The emerging situation raises the need to scientifically justify the practice of effective management of social programming (Terziev, Dimitrova, Stoyanov, 2015, pp. 9-25) and the creation or adaptation of models for adequate control, compliant with two aspects:

Firstly, on the concept of social development and programming and its associated process as a public mechanism combining meaningful strategies with key state and public interests and guaranteeing the sovereignty of their integrity and unity as well as the balance between their individual programs and policies.

Secondly, related to the process of control as a continuous and timely process-level feedback to ensure the unity between the process of social programming itself, considered as a state doctrine and the specific program level of governance. However, ensuring that this unity is addressed not only as a result of the implementation of social programming but also as a factor for its development and updating in line with 
changing social environment conditions.

An adequate proposal, which as a concept would make it possible to manage effectively and to control objectively, is the strategic map. The analysis shows that, both as a model and as a feasibility and as a visual and potential, the model of the BSC has a real opportunity to find the balance between the needs of social governance and the stated expectations of society. Seen and purely formal, the classic perspectives of the model created by Kaplan and Norton create opportunities to complement them with key perspectives of socio-economic development.

In addition to what has been said about the implementation of the BSC model in improving the management and control of the public sphere, it is also worth noting the role of the BSC in the project work. Building on the understanding that active social programs are systems of social projects and events with a direct relation and feedbacks of social interaction, which determines the opportunities of adaptation of their components to the new conditions and expectations, it can be said that they are social phenomena that occur in the form of a process and possess strategy features. In this context, it can be concluded that they evolve and change in a specific way the concept of self-perpetuating organization on the one hand, and on the other, perceiving the corrected real-life realities. But here is another very important thing, namely that in the present almost all the socially important ideas find their material realization in the form of results of a project.

Generally, the BSC is recognized to have very large application capabilities, addressing both management and control of various organizational structures and their parts, operations, and processes. As an application in the project activity, the model is aimed at evaluating the overall lifecycle of individual projects as well as the portfolio of projects, i.e. the project portfolio for organizations and a program of projects when it comes to the state.

Good practices provide information that, for project-oriented functionality, the BSC can contain four perspectives - financial, customer, inner processes, innovation and development (Stoyanov, 2011). Regarding this, the evaluation of the portfolio (program) of projects in the project-oriented organization, regardless of the scale, is proving to reproduce the following effects:

a. The project portfolio adds value to the organization's results or to the importance of the social program.

b. The portfolio (program) generates benefits to the organization or the state.

c. Portfolio implies the improvement of a number of organizational activities, social policies and related practices.

d. Models are developed as a benchmark of best practices for managing a portfolio of projects.

The goals of the BSC used in the evaluation of the project portfolio are as follows:

a. providing a situation where indicators represent key values and practices of the project-oriented organization.

b. developing robust business measures to assess the success of projects throughout their life cycle.

From the written about the application of the BSC in the project practice it can be said in general that they are intended for:

a. Creating an assessment of the extent to which individual projects are consistent with the strategic vision of the project-oriented organization.

b. An estimate of the level of utility of the individual projects in the portfolio shall be made.

c. Making a full evaluation of the projects in terms of their contribution as part of the overall results.

d. Evaluating the quality and competence in managing the individual projects and the organizational portfolio and identifying the alternatives for its improvement.

The above discussion provokes the following implications:

1. The main role of the BSC as a tool for strategic management and control is related to their essence of an operationalized and synthesized expression of the strategy, which provides prerequisites good enough for metering its realization. The model of the BSC, which envisages the localization of the key success factors and the resulting controllable parameters, their target values and the initiatives for their implementation, is considered as a basis for regulating and controlling the realization of the strategy. As far as this model is seen as a function of a strategy already in place, the BSC is fully fed into the strategy's views as a model, a plan and as a tool for implementing the strategy. In principle, this role of the BSC serves the manifestation of 
the control as a feedback at a strategic level.

2. BSCs as a tool for strategic control fully fit into the existing views of the elements of the control function. The main novelty they introduce, as mentioned, is related to the applied theoretical and practical approaches for operationalization of the system norm in a strategic aspect, i.e. with respect to the first element of the control function. In this respect, it should be stressed the leading role of this element in the manifestation of control in different fields and at different organizational levels. Until the appearance of BSCs, this element of the control function is either fragmentarily or absent in the theoretical developments about the structure of the control function (Terziev, Dimitrova, Stoyanov, 2015, pp.9-25).

3. The technology of developing BSC at the same time creates sufficient prerequisites for their active role as a tool for effective management and control over the very process of formulating the strategy. This role can be significant even in terms of the concepts of strategy being implemented as a model or as a plan. This is because in the process of operationalizing the strategy and determining the key controllable parameters included in the BSC it is necessary to prove the causal relationship between them and the impact of the changes in their meanings on the organization's target results. Practice shows that in most cases this leads to rethinking, redefining and refining the strategy itself. In this sense, the development of the BSC sends back control signals to the strategy itself, i.e. plays the role of a positive feedback in the process of its improvement even before its implementation.

4. As a synthesis of the strategy, the BSC is no analogue among the well-known strategic tools for the clear, concrete and accessible presentation of strategic intentions among wide circles of organizational staff at all organizational levels. In this context, the BSC can be seen as an instrument for implementing the concept of the learning organization. From this point of view, the process of developing the BSC down the hierarchical s.tructure of the organization can be seen as a process of controlling the perceptions of different categories of staff about success factors and ways to master them. In other words, as a tool for strategic management and control, the BSC creates preconditions not only for the analysis and control of behavior but also for its deep conditioning in the face of the intellectual models of success. Again, this is a feedback role that makes it easy for senior management to understand the strategy and the ways for its implementation at the different levels of the organization, and initiates measures to manage the perception of problems and regulate all this understanding.

5. The use of the BSC as a tool for organizational communication in accordance with the concept of the learning organization creates favorable prerequisites for the manifestation of the control over the implementation of the strategy as a positive feedback. As a clear, concrete, and accessible expression of the strategy, the BSC not only conveys the strategic intentions from the top down the organization hierarchy, but also pulls up the initiatives to change the strategy from bottom to top. In this sense, the BSC plays the role of a tool that is predominant to control the adequacy of the strategy in the process of its realization. From this point of view, it is necessary to conclude that, as a strategic control tool, the BSC is capable of equally well serving both the application of strategy concepts as a plan, and the application of the concept of strategy as emerging or developing. This makes the card a universal tool for management and control, which is organically integrated into the implementation of contemporary views on strategic management, regardless of their specificities and differences.

\section{CONCLUSION}

The analysis of the place and role of the BSC in the process of strategic management and control, as well as the active presence of the model in the improvement of intangible assets, provides the basis for several general conclusions (Terziev, Stoyanov, 2017c, pp. 229-232; Terziev, Stoyanov, 2017d, pp. 232-237; Terziev, Stoyanov, 2017e, pp. 237-242; Terziev, Stoyanov, Georgiev, 2017d, pp. 7-11; Terziev, Stoyanov, Georgiev, 2017e, pp. 239-243, Terziev, Stoyanov, Georgiev, 2017a, pp. 423-459; Terziev, Stoyanov, Georgiev, 2017b, pp. 492-522; Terziev, Stoyanov, Georgiev, 2017f, pp. 55-61; Terziev, Stoyanov, Georgiev, 2017g, pp. 61-68; Terziev, Stoyanov, 2017f, ст. 212-215; Terziev, Stoyanov, 2017g, pp. 410-413; Terziev, Stoyanov, Georgiev, 2017c, pp. 189-203; Terziev, Stoyanov, 2017a, pp. 622-626; Terziev, Stoyanov, 2017b, pp.616-621; Terziev, Stoyanov, 2017c, pp. 611-615):

1. BSC, interpreted as a strategic management and control tool, as control-management technology or as a synthesized expression of a stated strategy, provides an opportunity to show how concrete actions are transformed into a strategy and the way in which organizational performance from concrete results becomes a way of thinking and the basis of a structuring management doctrine. The logic construction model of the success factors - key indicators and their dependencies - target values of the indicators - strategic initiatives to achieve the target values creates extremely favorable prerequisites for the formation and alignment of the intellectual models in the modern organization. This behavior responds to the challenges of formulating new 
strategies and declaring new missions and concepts to deliver increased value to the customer. Specifically, the implementation of the BSC model identifies the solution to the problem faced by a large number of modern organizations, namely their inability to successfully carry out their stated strategies.

2. Building a complete understanding of the essential feature and functional capabilities of BSC affirms the understanding that it is a model that provides the most dense adaptation to stated specific strategies of any modern organization and shows how intangible assets generate an improvement in the organizational efficiency of internal organizational processes which have a crucial role to play in creating value for customers, shareholders and society. The large scope of action and the proven ability to measure the behavior and the value of heterogeneous indicators by establishing causal dependencies justifies the model being perceived and imposed as revolutionary and significant in terms of both measurement and management, and related control and on results and strategies.

3. Critical review of evolution in the modeling of BSC and extending its applications provides a solution to a key problem for the managers of all sectors of social development - a problem related to the relationship between strategies and intangible assets. On the one hand, the BSC demonstrates how the mobilization of human capital and the improvement of information resources increase the ability of modern organizations to generate value, and on the other hand - the rethinking of BSC based on the development of organizational capital provides an opportunity for organizational actions to find full compliance new strategies meeting the high requirements of its informed and demanding customers. In this way, the creation of high integrity and maximum coherence between key intangible assets and overall organizational activity, subject to the stated and necessary strategies, would create conditions for continuous improvement of organizations and more stable social development.

4. The analysis of the application of the BSC in its various events and models provides the opportunity to look for ways and in the context of social governance and on the necessary control to think and work. Reinforcing the relationship between state and organizations shows that the results that society expects can only be obtained through the rational use of upgrading models such as the BSC that not only increase the effectiveness of interaction across the entire social hierarchy but also develop the key for the whole society assets predominantly manifested through human, information and organizational (social) capital.

In conclusion, the conceptual and model development of the BSC confirms that the intangible capital of the organization is more important and essential than the physical capital. It is a basis for development of all organizations in the narrower sense, and for the whole society at a wider level, regardless of the level and the direction of its change. The introduction of a balanced method of managing and controlling the strategic process allows to analyze the results achieved and to use the most favorable opportunities for realization and prosperity in the dynamic conditions. On the other hand, the process of developing BSC proposals creates essential prerequisites for their improvement. A broad discussion aims to achieve consensus on the final parameters of the indicators in the BSC and to realize a backward impact, including on the individual intellectual models. Based on this, BSC can be validated and perceived with conviction as a guide to action, as a challenge for analysis, as an alternative to improvement and as a method, primarily for effective management under difficult conditions and a mandatory control.

\section{REFERENCES LIST}

Muller A. (2000). Strategisches Management mit der Balanced Scorecard. Stuttgart, 2000.

Stoyanov, E., Tranev, S. (2016). The truth about a social dilemma or the solution of a management problem. American Journal of Science and Technologies, N 1(21), Princeton University Press.

Stoyanov, E. (2016b). Control of organizational success or a strategy to improve the factor „knowledge”. The teacher of the future Ninth International Scientific Conference, International journal Knowledge, Vol. 13.2.

Stoyanov, E. (2016d). Social programming in contemporary society - an alternative in strategic management. Tenth International Scientific Conference The power of knowledge, International Journal Knowledge, Vol.14.1.

Stoyanov, E. (2016e). Opportunities of modern understandings on human capital. Journal of Economic Development, Environment and People 5-4.

Stoyanov, E. (2016f). Active social programs and their strategic advantages in labor market development. 
Journal of Economic Development, Environment and People 5-1.

Stoyanov, E. (2011). Upravlenie i kontrol na proekti. Libra Skorp, Burgas.

Goldenberg, H., Hoffecker, J. (1994). Using the Balanced Scorecard to develop companywide performance measures. Journal of Cost Management.

Friedag, H.R., Schmidt, W. (1999). Balanced Scorecard - Mehralsein Kennzahlensystem, RHV, FrlG.

Ehrmann, H. (2000) Kompakt - Training Balanced Scorecard, Ludwigshafen.

Mintzberg, H., Ahlstrand, B., \& Lampel, J. (1997). Strategy safari. a guided tour throut the wilds of strategic management. L.

Mintzberg, H., Ahlstrand, B., \& Lampel, J. (1997). Strategy safari. a guided tour throut the wilds of strategic management. L.

Kaplan, R., Norton D. (1992). The Balanced Scorecard: measures that drive performance. Harvard Business Review, I-II.

Kaplan, R., Norton D. (1993). Putting the Balanced Scorecard to work. Harvard Business Review.

Eccles, R., Pyburn, P. (1992). Creating a comprehensive system to measure performance. Management Accounting, $\mathrm{X}$.

Simons, R. (1995). Levers of control: how managers use innovative control systems to drive strategic renewal. Boston: Harvard Business School Press.

Terziev, V. Stoyanov, E. (2015). Vyzovy upravlencheskogo kontrolya v protsesse sotsialnogo programmirovaniya. Novosibirsk.

Terziev, V., Stoyanov, E. (2015a). Dependencies between social programming as a basis of regulating social development and the concept of controlling. Fifth international scientific and applicative conference Knowledge - who and what, Journal of Process Management (JPMNT) - New Technologies, International, Special Edition, Volume 9.

Terziev, V., Dimitrova, S., \& Stoyanov, E. (2015). Assessment of social programming efficiency in dynamic social environment. Journal of Innovations and Sustainability, Vol. 1, No 1.

Botta, V. (2001). Balanced Controlling //IS-Report 3.

Terziev, V., Stoyanov, E. (2015b). Management control as an effective instrument in implementation of the social program as a product of social programming. Fifth international scientific and applicative conference Knowledge - who and what, Journal of Process Management (JPMNT) - New Technologies, International, Special Edition, Volume 9.

Terziev, V., Dimitrova, S., \& Stoyanov, E. (2015). Development of active social programs. Journal of Innovations and Sustainability, Vol.1, No1.

Terziev. V., E. Stoyanov, Marin Georgiev (2017), Sbalansirovanaya map, how the alternative to malo business, International Science Journal "Innovative Science" №2 / 2017.Terziev. V., E. Stoyanov, M. Georgiev (2017a), The factotor information in the making of „The right“ decision, Scientific journal "Economics and finance“", Publishing house „BREEZE“.

Terziev. V., E. Stoyanov, M. Georgiev,(2017b) One solution for costs minimanization in the banking sector, Scientific journal „Economics and finance”, Publishing house „BREEZE“.

Terziev. V., E. Stoyanov, M. Georgiev (2017c), Institutional team work-opportunity for improvement of financial control, Scientific journal „Economics and finance“, Publishing house „BREEZE“.

Terziev. V., E. Stoyanov (2017a), Functional Characteristics and Development Ideas Control, International Science Journal Internauka.

Terziev. V., Stoyanov. E. (2017b), Formation of audience and institutionalization, International Science Journal Internauka.

Terziev, V., E. Stoyanov, (2017c) Instruments for evaluating the financial efficiency of social programs, Fiscal and credit system: vector of rosters, Master of Science II International Scientific and Practical Conference, Uzhgorod.

Terziev, V., E. Stoyanov, (2017d) Model financial assessments of social programs, Fiscal and credit system: 
vector of growth, Secondary scientific and practical conference, Uzhgorod.

Terziev, V., E. Stoyanov (2017e), Financial Evaluation of Social Effectiveness, Financing-Credit System: Vector Growth, International Journal of Social Science, UzhgorodTerziev. V., Stoyanov E., Georgiev M. (2017d), The balanced scorecard model as atool for improvement of the national defense system management, Research: tendencies and prospects: Collection of scientific articles. - Editorial Arane, S.A. de C.V. 